\section{Commentary: Surgical explant of TAVR prostheses}

\author{
J. James Edelman, PhD, FRACS, ${ }^{a}$ and \\ Vinod H. Thourani, $\mathrm{MD}^{\mathrm{b}}$
}

A paradigm shift has occurred in the management of severe aortic stenosis, with the number of transcatheter aortic valve replacement (TAVR) procedures overtaking all surgical aortic valve replacements in the United States in 2017 (American College of Cardiology/Society of Thoracic Surgeons [STS] Transcatheter Valve Therapy Registry, private communication, June 30, 2020). The Food and Drug Administration approval for all patient risk cohorts in August 2019 will further contribute to this shift toward increased TAVR procedures. To date, and despite the large number of TAVR valves placed annually, the largest series from the STS database includes only 123 patients. ${ }^{1}$ Most of the patients in that cohort were high risks $(59 \%$ had an STS predicted risk of mortality $>8 \%$ ) and had undergone explantation because of early device failure (paravalvular regurgitation), structural valve deterioration (SVD; 11\%), failed repair $(11 \%)$, sizing or positioning issues $(11 \%)$, and prosthetic valve endocarditis $(10 \%)$. Mortality was greater than expected, with an observed/expected ratio $>1$.0. Progress with TAVR-in-TAVR for SVD and endovascular plugging for paravalvular regurgitation might further limit the need for surgical explantation of TAVR valves. However, other indications, for example, for endocarditis, will continue to be best treated with surgery.

In this issue of JTCVS, Nakazato and colleagues ${ }^{2}$ have described their technique for removal of

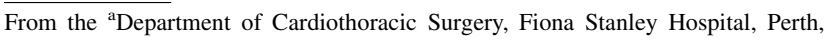
Western Australia, Australia; and ${ }^{\mathrm{b}}$ Department of Cardiovascular Surgery, Marcus Valve Center, Piedmont Heart Institute, Atlanta, Ga.

Disclosures: The authors reported no conflicts of interest.

The Journal policy requires editors and reviewers to disclose conflicts of interest and to decline handling or reviewing manuscripts for which they may have a conflict of interest. The editors and reviewers of this article have no conflicts of interest.

Received for publication June 22, 2020; revisions received June 22, 2020; accepted for publication June 27, 2020; available ahead of print June 30, 2020

Address for reprints: Vinod H. Thourani, MD, Department of Cardiovascular Surgery, Piedmont Heart Institute, 95 Collier Rd, Suite 5015, Atlanta, GA 30308 (E-mail: vinod.thourani@piedmont.org).

JTCVS Techniques 2020;3:75-6

2666-2507

Copyright (C) 2020 The Authors. Published by Elsevier Inc. on behalf of The American Association for Thoracic Surgery. This is an open access article under the CC BY-NCND license (http://creativecommons.org/licenses/by-nc-nd/4.0/).

https://doi.org/10.1016/j.xjtc.2020.06.042
}

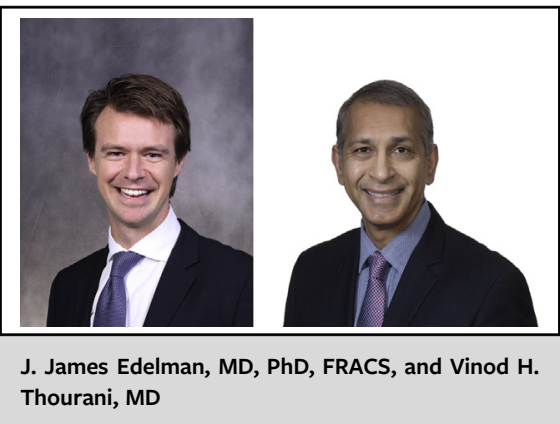

CENTRAL MESSAGE

As transcatheter aortic valve replacement (TAVR) extends to lower risk and younger patients, the need to explant TAVR valves for SVD will increase. These complex procedures could require aortic root or concomitant mitral valve surgery.

balloon-expandable TAVR prostheses. They described cutting the stent frame longitudinally and rolling the valve inward on a Kelly clamp to reduce the radial force and allow for dissection in a plane between the prosthesis and native annulus. We have had success removing both balloon- and self-expanding valves using a similar technique. The native aortic valve leaflets offer a margin of safety from which to dissect the prosthesis away and allow room for the longitudinal incision. Interestingly, when faced with a TAVR-inTAVR removal, the authors were able to separate each TAVR prosthesis and remove them separately. ${ }^{2}$ In a similar case, we had incised both layers of the stent longitudinally with wire cutters and were able to explant both valves together.

A slight alteration to the technique is required for removal of self-expanding prostheses, which extend distally beyond the sinotubular junction and will most often be incorporated into the aortic wall after $\sim 6$ months. In a short ascending aorta, cannulation for cardiopulmonary bypass might need to be performed more distally in the arch to allow for separation between the aortic cross-clamp and aortotomy, which must be well clear of the distal end of the prosthesis. We have found that transecting the aorta in explanting self-expanding valves can be useful to assist in performing the "endarterectomy" of the prosthesis from the aortic wall. 
As the use of TAVR extends to younger and lower risk populations, the need to surgically remove TAVR valves because of a variety of complications or SVD will increase. Most often, this can be achieved without injury to the aorta, aortic root, or mitral valve apparatus. However, these structures are vulnerable, especially when prostheses have been placed low or have been implanted for a prolonged period, leading to incorporation of the TAVR into the aortic walls or anterior leaflet of the mitral valve. Surgeons must be ready to offer this procedure with minimal morbidity and mortality. Thus, familiarity with surgery of the aortic root and mitral valve will be essential.

\section{References}

1. Jawitz OK, Gulack BC, Grau-Sepulveda MV, Matsouaka RA, Mack MJ, Holmes DR Jr, et al. Reoperation after transcatheter aortic valve replacement. JACC Cardiovasc Interv. 2020 [Epub ahead of print].

2. Nakazato T, Toda K, Kuratani T, Sawa Y. Redo surgery after transcatheter aortic valve replacement with a balloon-expandable valve. J Thorac Cardiovasc Surg Tech. 2020;3:72-4. 